\title{
Peptide Ring Closing Metathesis: Minimizing Side Reactions in Arodyn Analogs
}

\author{
Solomon A. Gisemba ${ }^{1,2}$ and Jane V. Aldrich ${ }^{1,2}$ \\ ${ }^{1}$ Department of Medicinal Chemistry, The University of Kansas, Lawrence, KS, 66045, USA; \\ ${ }^{2}$ Department of Medicinal Chemistry, University of Florida, Gainesville, FL, 32610, USA
}

\section{Introduction}

Kappa $(\kappa)$ opioid receptor (KOR) ligands, particularly antagonists, have received increasing attention due to their therapeutic potential in stress related conditions [1]. The acetylated dynorphin A (Dyn A) analog arodyn (Ac[Phe $\left.{ }^{1,2,3}, \mathrm{Arg}^{4}, \mathrm{D}-\mathrm{Ala}^{8}\right] \mathrm{Dyn} \mathrm{A}(1-11)-\mathrm{NH}_{2}$, Figure 1), shows potent KOR antagonism in vitro. Arodyn has high affinity $\left(\mathrm{K}_{\mathrm{i}}=10 \mathrm{nM}\right)$ and selectivity $\left(\mathrm{K}_{\mathrm{i}}\right.$ ratio $\left.(\kappa / \mu / \delta)=1 / 174 / 583\right)$ for KOR [2]. Clinical development of KOR antagonists has been hampered partly because prototypical small molecule KOR antagonists such as JDTic exhibit long-lasting antagonism, lasting for weeks after a single dose [1]. Conversely, linear peptide KOR antagonists such as arodyn are rapidly metabolized and inactivated. Conformational constraint of the flexible linear peptide by ring closing metathesis (RCM) cyclization was expected to enhance its metabolic stability and potentially stabilize the bioactive conformation. Aromatic residues in arodyn contribute to affinity at KOR [4]; we are exploring RCM cyclization employing $\mathrm{Tyr}(\mathrm{All})$ residues which retain the aromatic nature of the $N$-terminal region.

In contrast to high yields observed in RCM using allylglycine in Dyn A analogs [5], a mixture of side products (Figure 2) compromised the

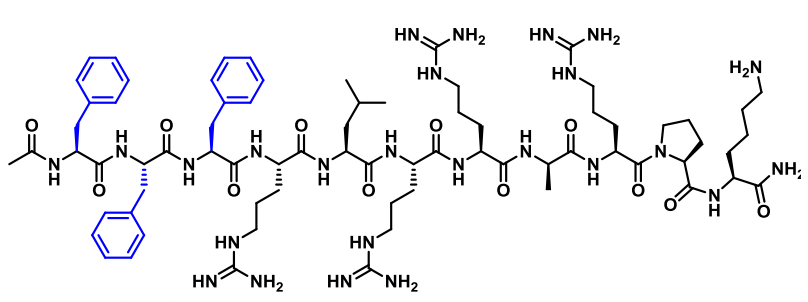

Ac-Phe-Phe-Phe-Arg-Leu-Arg-Arg-D-Ala-Arg-Pro-Lys- $\mathrm{NH}_{2}$ Arodyn

H-Tyr-Gly-Gly-Phe-Leu-Arg-Arg-Ile-Arg-Pro-Lys-OH

Dynorphin A(1-11)

Fig. 1. Structure of arodyn and dynorphin A (1-11), a fragment of the endogenous KOR ligand.
$\mathrm{RCM}$ product yield of arodyn analogs containing Tyr(All) [4]. Olefin isomerization due to degradation products of the Grubbs catalyst could lead to the observed side products [6].

A model dipeptide, Fmoc-Tyr(All)Tyr(All), was employed to explore reaction conditions to enhance yields of the cyclic RCM product, conditions which were subsequently applied to arodyn analogs. Here, we present the results of different strategies to minimize the side reaction, including examination of reagents reported to suppress isomerization $[6,7]$ as well as microwave heating.

\section{Results and Discussion}

The model peptide was synthesized by standard Fmoc SPPS and cyclized on resin using second generation Grubbs catalyst (G II). The reaction conditions used for arodyn analogs containing allylglycine $\left(40 \mathrm{~mol} \%\right.$ and $3 \mathrm{mM}$ of catalyst at $60^{\circ} \mathrm{C}$ for 2 days) [5] gave only $20 \%$ of the desired RCM

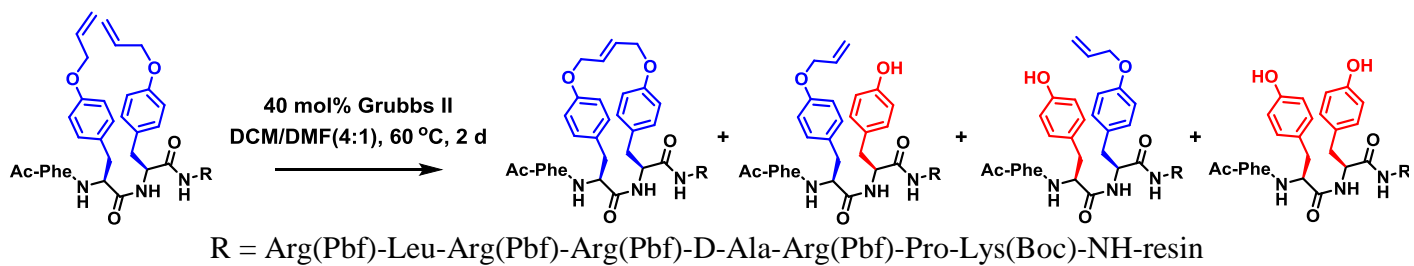

Fig. 2. Products resulting from RCM of [Tyr (All $\left.)^{2,3}\right]$ arodyn. 
product for the model dipeptide plus a number of desallyl side products (Figure 2), as determined by HPLC. Different reaction parameters and strategies to enhance the yield of the RCM product were then examined on the model dipeptide. Generally, higher yields of the RCM product were observed at a lower temperature $\left(40^{\circ} \mathrm{C}\right)$ in the presence of phenol and at a low catalyst concentration $(0.3 \mathrm{mM})$ in dichloromethane. A four-fold increase in yield was observed under the optimized conditions with the model dipeptide. A similar increase in yield was observed when second generation Hoveyda-Grubbs catalyst (HG II) was used under the optimized reaction conditions. Unlike G II, HG II was active at a higher temperature $\left(60^{\circ} \mathrm{C}\right)$, presumably due to its higher stability compared to G II [8].

The optimized conditions when applied to [Tyr(All) $\left.{ }^{2,3}\right]$ arodyn gave much higher yields $(56-71 \%)$ of the cyclic product compared to the initial conditions (30\%). The highest yields were observed using G II (71\%), and thus G II was used in the synthesis of subsequent analogs containing Tyr(All) or $m$-Tyr(All). In initial reactions, reasonable yields $(52-64 \%)$ of the cyclic products were obtained for $\left[\operatorname{Tyr}(\mathrm{All})^{2}, m-\operatorname{Tyr}(\mathrm{All})^{3}\right]-,\left[m-\operatorname{Tyr}(\mathrm{All})^{2,3}\right]-$, and $\left[\operatorname{Tyr}(\mathrm{All})^{1,2}\right]$ arodyn. However, lower yields were observed for $\left[m\right.$-Tyr $\left.(\mathrm{All})^{2}, \operatorname{Tyr}(\mathrm{All})^{3}\right]$ - and $\left[\operatorname{Tyr}(\mathrm{All})^{1}, m\right.$-Tyr $\left.(\mathrm{All})^{2}\right] \operatorname{arodyn}(22-35 \%)$ where $m$-Tyr(All) is the second residue of arodyn. Generally, the olefins were in the trans configuration. A negligible amount $(<10 \%)$ of the cyclic product was observed for [Tyr(All) $\left.)^{1,3}\right]$ arodyn.

Microwave heating was also examined as a strategy to increase the yield of the RCM products. In preliminary studies, negligible yields of the RCM product were observed when G II was used, whereas HG II gave high yields under both closed and open-vessel microwave heating at $60^{\circ} \mathrm{C}$ in dichloroethane. HG II was therefore used in subsequent microwave assisted RCM. Moderate to high yields (44-72\%) were observed under microwave heating with reduced reaction times $\left(3-5 \mathrm{~h}\right.$ at $\left.60^{\circ} \mathrm{C}\right)$ compared to conventional heating $\left(2 \mathrm{~d}\right.$ at $\left.40^{\circ} \mathrm{C}\right)$. Notably, a two-fold increase in yield was observed for $\left[\operatorname{Tyr}(\mathrm{All})^{1}, m\right.$-Tyr(All) $\left.{ }^{2}\right]$ arodyn $(44 \%)$ under microwave heating. However, a negligible yield of [Tyr(All) $)^{1,3}$ ]arodyn $(<10 \%)$ was still observed. Pharmacological evaluation of the synthesized RCM products is in progress.

In summary, using the optimized RCM conditions developed for the model dipeptide generally resulted in higher yields of arodyn analogs containing $\operatorname{Tyr}(\mathrm{All}) / m$-Tyr(All). While sequence dependent effects were observed under both microwave and conventional heating, microwave heating offered the advantage of shorter reaction times for generally comparable yields compared to conventional heating.

\section{Acknowledgments}

We thank Dmitry Yakovlev for assistance in HPLC analysis and Justin Douglas of the University of Kansas NMR laboratory for assistance with configurational assignments based on NMR data. Research supported by grant R01 DA018832 (National Institute on Drug Abuse).

\section{References}

1. Aldrich, J.V., et al. AAPS J. 11, 312-322 (2009), http://dx.doi.org/10.1208/s12248-009-9105-4

2. Bennett, M.A., et al. J. Med. Chem. 45, 5617-5619 (2002), http://dx.doi.org/10.1021/jm025575g

3. Bennett, M.A., et al. J. Pept. Res. 65, 322-332 (2005), http://dx.doi.org/ 10.1111/j.1399-3011.2005.00216.x

4. Fang, W.J. et al., in Valle, D.S. et al. (Ed.) Peptides: Peptides for Youth (Proceedings of the 20th American Peptide Symposium), American Peptide Society, Montreal, 2009, p. 279, http://dx.doi.org/10.1007/978-0-38773657-0

5. Fang, W.J., et al. J. Med. Chem. 52, 5619-5625 (2009), http://dx.doi.org/10.1021/jm900577k

6. Hong, S.H., et al. J. Am. Chem. Soc. 127, 17160-1716 (2005), http://dx.doi.org/10.1021/ja052939w

7. Schmidt, B., Hauke, S. Org. Biomol. Chem. 11, 4194-4206 (2013), http://dx.doi.org/10.1039/c3ob40167g

8. Vougioukalakis, G.C., Grubbs, R.H. Chem. Rev. 110, 1746-1787 (2010), http://dx.doi.org/10.1021/cr9002424 